\title{
Normative Nasalance Scores for Brazilian Portuguese Using New Speech Stimuli
}

\author{
Viviane Cristina de Castro Marino ${ }^{a}$ Jeniffer de Cássia Rillo Dutka ${ }^{b}$ \\ Gillian de Boer ${ }^{c}$ Vanessa Moraes Cardoso ${ }^{a}$ Renata Giorgetto Ramos ${ }^{a}$ \\ Tim Bressmann ${ }^{c}$ \\ aspeech-Language and Audiology Department, Universidade Estadual Paulista 'Júlio de Mesquita Filho' (UNESP), \\ Marília, and 'Speech-Language and Audiology Department, Faculdade de Odontologia de Bauru and Graduate \\ Programs at the Universidade de São Paulo (USP), Bauru, Brazil; ' Department of Speech-Language Pathology, \\ University of Toronto, Toronto, Ont., Canada
}

\section{Key Words}

Nasometry · Nasalance scores · Nasometer · Brazilian

Portuguese $\cdot$ Cleft palate $\cdot$ Speech

\begin{abstract}
Objective: Normative data were established for newly developed speech materials for nasalance assessment in Brazilian Portuguese. Materials and Methods: Nasalance scores of preexisting passages (oral ZOO-BR, low-pressure oral ZOOBR2 and NASAL-BR), new nasalance passages (oral Dudu no zoológico, oral Dudu no bosque, oral-nasal O cãozinho Totó and nasal $O$ nenê) and Brasilcleft articulation screening sentences were collected from 245 speakers of Brazilian Portuguese, including 121 males and 124 females, divided into 4 groups: children (5-9 years), adolescents (10-19 years), young adults (20-24 years) and adults ( $25-35$ years). Results: Across all nasalance passages, adult females scored on average 2 percentage points higher than males. Children scored 2-4 percentage points lower than older groups for the preexisting nasalance passages ZOO-BR and ZOO-BR2. Nasalance scores for the new nasalance passages were not significantly different from the preexisting passages. Scores for high-pressure sentences did not differ significantly from the oral nasalance passage Dudu no bosque. Conclusion: The na-
\end{abstract}

(c) 2016 S. Karger AG, Basel

$1021-7762 / 16 / 0675-0238 \$ 39.50 / 0$ salance scores for the new nasalance passages were equivalent to the preexisting materials. The new shortened and simplified nasalance passages will be useful for assessing young children. Normative scores for the Brasilcleft highpressure sentences were equivalent to the new oral passage Dudu no bosque.

(c) 2016 S. Karger AG, Basel

\section{Introduction}

Cleft palate can affect the patient's speech in different ways. On the one hand, it may affect velopharyngeal closure, resulting in hypernasality and other disorders of oral-nasal balance [1] and, on the other hand, many patients with cleft palate also develop articulation errors. These can be passive (i.e., related to structural deficits such as palatal fistulae) or active (i.e., resulting from compensatory learning such as glottal stops) [2]. The clinician evaluates oral-nasal balance and articulation, using auditory-perceptual and instrumental assessments.

A speaker's oral-nasal balance is assessed perceptually and documented on rating scales $[3,4]$. While a thorough auditory-perceptual assessment is indispensable and supersedes any instrumental measures [1], quantitative in-

Viviane Cristina de Castro Marino, $\mathrm{PhD}$

Department of Speech-Language and Audiology

Universidade Estadual Paulista 'Júlio de Mesquita Filho' (UNESP)

Rua Julio de Mesquita Filho, 737, Marília, SP 17.525-000 (Brazil)

E-Mail karger@karger.com

E-Mail vivianemarino2@yahoo.com.br 
strumental measures serve to corroborate and augment the perceptual assessment $[5,6]$. A commonly used instrumental adjunct to the assessment of oral-nasal balance is the nasalance measure obtained with a nasometer or similar instrument. The Nasometer (Kay Elemetrics Corporation, Lincoln Park, N.J., USA) quantifies nasalance as the ratio of nasal acoustic energy to the sum of nasal plus oral acoustic energy, expressed as a percentage. Measures of nasalance have been used to document oralnasal balance in numerous clinical populations, including cleft palate, neurogenic dysarthrias and hearing impairment [7-13].

In order to record nasalance scores, the participant reads or repeats specific speech stimuli. For North American English, the Zoo Passage (only oral speech sounds) is used to assess hypernasality and the Nasal Sentences (loaded with nasal consonants) are used to assess hyponasality. The Rainbow Passage by Fairbanks [14] is a stimulus with a normal distribution of oral and nasal speech sounds. Perceptually, high nasalance scores for oral passages usually correlate with hypernasality, while low nasalance scores for nasal sentences usually correlate with hyponasality [6]. Similar speech stimuli have been developed for different languages around the world, including Brazilian Portuguese [15]. Trindade et al. [15] developed 4 passages and established norms for speakers of Brazilian Portuguese. These passages are the oral text passage ZOO-BR, the alternative oral text passage ZOO-BR2 with only low-pressure consonants, the nasal text passage NASAL-BR (loaded with nasal consonants) and the alternative nasal text passage NASAL2-BR without pressure consonants. A stimulus representing the normal distribution of oral and nasal speech sounds for Brazilian Portuguese was not provided by Trindade et al. [15].

The original nasalance stimuli by Fletcher [16] and the Brazilian Portuguese stimuli by Trindade et al. [15] work well for older and literate speakers. However, many patients with cleft palate are younger and often preliterate, so the text passages may be difficult to record. For American English, a number of shorter and simplified stimuli have been developed for children [17-19]. It would be desirable to have similar shortened and simplified assessment materials for Brazilian Portuguese. Di Ninno et al. [20] suggested using the single word 'papai', but this word could only be used to assess hypernasality, and a short stimulus may have low criterion validity [19]. It was one goal of the present study to develop new simplified nasalance stimuli for Brazilian Portuguese.

Another important aspect of cleft palate speech is the patient's articulation. In recent years, there has been a push to develop standardized materials so that outcomes between cleft centers can be better compared [21, 22]. Henningsson et al. [4] defined specific criteria for articulation screening stimuli to ensure that speakers of different languages can be compared in international studies. Based on these recommendations, a group of speech-language pathologists [23] developed 18 sentences (12 high-pressure, 3 low-pressure and 3 nasal sentences) to evaluate the consonants of Brazilian Portuguese. The screening sentences will allow Brazilian cleft centers to collect speech data for national and international outcome studies.

Not all cleft centers in Brazil have nasometers, and it is expected that many centers will base their auditory-perceptual assessments exclusively on the articulation screening sentences. Ideally, the same stimuli should be used for the auditory-perceptual and the nasometric assessment [24]. However, the existing Brazilian nasalance stimuli [15] and the new stimuli proposed here were not designed for articulation screening, nor were the articulation screening sentences designed to measure nasalance. It was therefore necessary to assess whether the nasalance scores for the new nasalance stimuli were equivalent to the nasalance scores for the articulation screening sentences.

There are other variables such as the age and gender of the speaker that may influence nasalance values. Some studies have found lower nasalance values for children compared to adults [15, 25-27]. While some previous studies have found no effect of gender [15, 24, 25, 28-30], others have found slightly higher scores for female speakers $[6,31-33]$.

The first goal of this study was to establish normative values for a new set of simplified stimuli for nasalance measurement in Brazilian Portuguese. A second goal was to characterize the stimuli in terms of possible age and gender effects and establish orienting normative values in different age ranges. It was a third goal to ensure the equivalence of the new materials with the established stimuli by Trindade et al. [15]. The final goal of this study was to ensure that the nasalance scores for the articulation screening sentences were equivalent to the new nasalance stimuli, in order to ensure that clinicians can base their auditory-perceptual assessments of oral-nasal balance on the articulation screening sentences.

Based on these goals, there were a number of expectations for the research. It was expected that: (1) oral stimuli would have low nasalance scores, nasal stimuli would have high scores, and oronasal stimuli would be in between; (2) the nasalance scores across age groups and gender would be equivalent; (3) the scores for the new nasalance stimuli would be equivalent to the previous mate- 
rials by Trindade et al. [15], and (4) the nasalance scores for articulation screening sentences would be equivalent to the nasalance scores for the new nasalance stimuli.

\section{Methods}

\section{Participants}

The study was reviewed and approved by the Institutional Review Board at the Universidade Estadual Paulista 'Júlio de Mesquita Filho' in Marilia, SP, Brazil. Initially, 296 participants were recruited from local schools, universities and the community at large. Exclusion criteria were nasal congestion, hoarseness, articulation errors and the inability to read or, for the youngest participants, repeat the speech samples accurately. Based on these criteria, 51 subjects were excluded. The remaining 245 participants (121 males, 124 females) spoke the Brazilian Portuguese dialect typical for the Midwest region of São Paulo State as their first and only language. The participants were divided into 4 age groups (table 1 ) according to the World Health Organization classification [34].

\section{Speech Stimuli}

The stimuli included the oral ZOO-BR, low-pressure oral ZOOBR2 and NASAL-BR [15], the 4 new stimuli as well as the Brasilcleft articulation screening sentences [23]. The new speech stimuli consisted of 4 reading passages. The oral passage Dudu no zoológico (Dudu at the zoo, $82 \%$ oral pressure consonants) is comparable to the English Zoo Passage (Appendix 1). The simplified oral passage Dudu no bosque (Dudu at the park, $82 \%$ oral pressure consonants) is syntactically and semantically less complex than Dudu no zoológico (Appendix 2). The oral-nasal passage O cãozinho Totó (Toto the puppy) contained $15.9 \%$ nasal phonemes (Appendix 3), while the nasal passage $O$ nenê (The baby) contained $47.5 \%$ nasal consonants (Appendix 4). Based on previous corpus research [35], Brazilian Portuguese contains about $16 \%$ of nasal consonants, so the nasal text passage $O$ nenê had 3 times more nasal phonemes. Simplified alternatives for the low-pressure oral ZOO-BR2 and NASAL-BR2 passages [15] were not developed in the present study.

The Brasilcleftt articulation screening sentences [23] consisted of 18 sentences, each with a single target consonant (12 high-pressure, 3 low-pressure and 3 nasal sentences).

\section{Recording Procedures}

Nasalance scores were obtained using Nasometer II 6400 (KayPentax, Lincoln Park, N.J., USA) in a sound-treated laboratory. The Nasometer was calibrated prior to each day's data collection. The first author checked the separator plate for all participants to ensure level positioning throughout the assessment. Participants read the stimuli once at a comfortable pitch and loudness. Participants $\leq 7$ years old repeated the stimuli after the examiner. The order of the stimuli was held constant with the Brasilcleft sentences first, followed by the new nasalance stimuli (Dudu no zoo, Dudu no bosque, $O$ cãozinho Totó and $O$ nenê) and then the traditional speech stimuli (ZOO-BR, ZOO-BR2 and NASAL-BR). The Brasilcleft sentences were recorded in 3 separate blocks of 12 sentences with pressure consonants, 3 sentences with low-pressure consonants and 3 sentences with nasal consonants. Mean nasalance scores were recorded for the blocks of Brasilcleft sentences and the text passages.
Table 1. Gender and age distribution of the 245 participants

\begin{tabular}{|c|c|c|c|c|}
\hline & Children & Adolescents & $\begin{array}{l}\text { Young } \\
\text { adults }\end{array}$ & Adults \\
\hline Total, n (\%) & $57(23)$ & $61(24)$ & $65(27)$ & $62(26)$ \\
\hline Males & 27 & 30 & 34 & 30 \\
\hline Females & 30 & 31 & 31 & 32 \\
\hline \multicolumn{5}{|l|}{ Age } \\
\hline Mean & $7 \mathrm{y}, 8 \mathrm{~m}$ & $15 \mathrm{y}, 0 \mathrm{~m}$ & $22 \mathrm{y}, 2 \mathrm{~m}$ & $29 \mathrm{y}, 8 \mathrm{~m}$ \\
\hline $\mathrm{SD}$ & $1 \mathrm{y}, 1 \mathrm{~m}$ & $2 \mathrm{y}, 6 \mathrm{~m}$ & $1 \mathrm{y}, 4 \mathrm{~m}$ & $3 y, 2 \mathrm{~m}$ \\
\hline
\end{tabular}

$\mathrm{Y}=$ Years; $\mathrm{m}=$ months

\section{Data Analysis}

The data were analyzed using NCSS version 8.0 (NCSS LLC, Kaysville, Utah, USA). The effects of age, gender and stimuli on nasalance scores were assessed using repeated-measures analysis of variance (ANOVA) and post hoc Bonferroni pairwise comparisons. Where sphericity was violated, the Geisser-Greenhouse adjustment was applied. Two paired t tests compared Dudu no bosque to the high- and low-pressure articulation sentences. A third paired t test compared $O$ nenê to the nasal articulation sentences. The significance for the ANOVA and the post hoc comparisons was set to $\mathrm{p}=0.05$. The significance for the 3 paired $\mathrm{t}$ tests was Bonferroni corrected to $\mathrm{p}=0.017$.

\section{Results}

The mean nasalance scores, standard deviations and ranges for the different stimuli are shown in table 2. Data were obtained from all 245 participants for all speech stimuli with the exception of Dudu no bosque, which had 7 missing values from the young adult group ( 6 females, 1 male) and 1 missing value from a male adult.

A repeated-measures ANOVA of the nasalance scores was run for the 4 age groups, gender and the 7 stimuli. There was a main effect for gender $[\mathrm{F}(1,237)=20.12 ; \mathrm{p}<0.001]$ and stimulus $[\mathrm{F}(6,237)=10,643.34 ; \mathrm{p}<0.001]$, and an interaction effect for age by gender $[\mathrm{F}(3,237)=7.13$; $\mathrm{p}<$ $0.001]$ and age by stimulus $[\mathrm{F}(18,1,414)=5.09 ; \mathrm{p}<0.001]$.

For the main effect of gender, the mean nasalance score for females, across all age groups and stimuli, was $24.99 \%$ (SD 17.18), which was significantly higher than the mean of $23.09 \%$ (SD 17.28) for males. As for the main effect of stimuli, the mean nasalance score for the new oral stimulus ( $D u d u$ no zoo) was equivalent to that of $\mathrm{ZOO}-\mathrm{BR}$, the shortened oral stimulus (Dudu no bosque) was equivalent to the low-pressure $\mathrm{ZOO}-\mathrm{BR} 2$, and the new nasal stimulus was equivalent to NASAL-BR. All remaining Bonferroni pairwise comparisons of stimuli means were significantly different from each other. 
Table 2. Mean nasalance scores (\%), SDs (\%) and ranges (\%) of nasalance scores for the 7 stimuli for 245 Brazilian speakers, according to their age group and gender

\begin{tabular}{|c|c|c|c|c|c|c|c|c|}
\hline \multirow[t]{2}{*}{ Stimuli } & \multicolumn{2}{|c|}{ Children } & \multicolumn{2}{|c|}{ Adolescents } & \multicolumn{2}{|c|}{ Young adults } & \multicolumn{2}{|l|}{ Adults } \\
\hline & male & female & male & female & male & female & male & female \\
\hline \multicolumn{9}{|c|}{ Oral passage } \\
\hline Mean & 10.41 & 9.1 & 9.77 & 10.81 & 9.36 & 11.62 & 8.7 & 13.38 \\
\hline SD & 3.33 & 2.90 & 3.47 & 3.38 & 4.04 & 3.45 & 3.52 & 4.46 \\
\hline Range & $5-17$ & $4-15$ & $5-19$ & $4-22$ & $4-26$ & $4-17$ & $3-19$ & $7-26$ \\
\hline \multicolumn{9}{|c|}{ Oral simplified passage ${ }^{1}$} \\
\hline Mean & 11.11 & 9.83 & 11.03 & 12.52 & 9.34 & 14.04 & 8.97 & 13.34 \\
\hline SD & 4.51 & 3.0 & 4.48 & 3.76 & 3.78 & 3.82 & 3.5 & 4.43 \\
\hline Range & $5-22$ & $4-16$ & $6-23$ & $6-19$ & $4-21$ & $6-21$ & $4-22$ & $6-22$ \\
\hline \multicolumn{9}{|c|}{ Oronasal passage } \\
\hline Mean & 26.89 & 26.33 & 24.67 & 26.80 & 24.90 & 26.90 & 24.53 & 28.31 \\
\hline SD & 3.20 & 4.24 & 3.7 & 3.05 & 3.93 & 4 & 4.16 & 4.50 \\
\hline Range & $21-32$ & $18-35$ & $18-33$ & $20-36$ & $19-37$ & $19-36$ & $17-35$ & $22-39$ \\
\hline \multicolumn{9}{|c|}{ Nasal passage } \\
\hline Mean & 49.93 & 49.67 & 48.23 & 49.19 & 49 & 49.37 & 46.07 & 51.13 \\
\hline SD & 5.2 & 5.82 & 3.39 & 4.59 & 4.2 & 4.69 & 5.45 & 4.86 \\
\hline Range & $33-58$ & $37-59$ & $42-55$ & $43-60$ & $42-60$ & $41-63$ & $34-59$ & $42-62$ \\
\hline \multicolumn{9}{|l|}{ ZOO-BR } \\
\hline Mean & 9.37 & 8.87 & 9.07 & 10.87 & 9.09 & 11.87 & 8.87 & 14.06 \\
\hline SD & 2.65 & 2.81 & 2.73 & 3.53 & 3.19 & 3.54 & 3.03 & 5.09 \\
\hline Range & $5-13$ & $4-16$ & $5-16$ & $5-21$ & $5-19$ & $4-20$ & $4-15$ & $7-26$ \\
\hline \multicolumn{9}{|l|}{ ZOO-BR2 } \\
\hline Mean & 10.19 & 9.10 & 11.57 & 12.35 & 11.12 & 14.46 & 10.93 & 16.16 \\
\hline SD & 3.89 & 2.92 & 4.61 & 4.61 & 3.63 & 5.67 & 3.72 & 5.73 \\
\hline Range & $4-20$ & $4-15$ & $6-26$ & $5-25$ & $6-21$ & $5-26$ & $4-18$ & $7-26$ \\
\hline \multicolumn{9}{|c|}{ NASAL-BR } \\
\hline Mean & 49.59 & 49.03 & 48.77 & 49.52 & 48.48 & 49.90 & 46.67 & 51.16 \\
\hline SD & 4.58 & 5.14 & 3.67 & 4.58 & 4.72 & 4.16 & 5.54 & 5.33 \\
\hline Range & $38-58$ & $39-61$ & $43-57$ & $42-57$ & $41-57$ & $41-57$ & $37-60$ & $39-61$ \\
\hline
\end{tabular}

${ }^{1}$ Oral simplified passage based on 237 speakers.

For the age-by-gender interaction effect, the mean nasalance score across the stimuli was significantly higher for the females in the oldest age group at $26.79 \%$ (SD 16.90 ) compared to $22.17 \%$ (SD 16.77) for the males. In terms of age by stimulus interaction, for ZOO-BR, the youngest age group's mean of $9.10 \%$ (SD 2.72) was significantly lower than the mean of $11.55 \%$ (SD 4.93) for the oldest age group. For the low-pressure ZOO-BR2, the youngest age group had a mean nasalance score of $9.61 \%$ (SD 3.43), which was significantly lower than those of the other age groups, whose means from second youngest to oldest were $11.97 \%$ (SD 4.59), 12.77\% (SD 5.01) and $13.63 \%$ (SD 5.49), respectively.

The nasalance scores of the new nasalance stimuli were compared to the Brasilcleft sentences with paired t tests. The mean of the high- and low-pressure (oral) articulation screening sentences was $11.44 \%$ (SD 3.92) and $12.05 \%$ (SD 4.75), respectively. Compared to the simpli- fied oral passage (Dudu no bosque) with a mean of $11.24 \%$ (SD 4.26), the low-pressure sentences were significantly higher $[\mathrm{t}(236)=2.63 ; \mathrm{p}=0.009]$, but the high-pressure sentences were not different $[\mathrm{t}(236)=0.92 ; \mathrm{p}=0.356]$. The articulation screening sentences for the nasal sounds had a mean nasalance score of $65.17 \%$ (SD 5.44), which was significantly higher than the new nasalance passage $(O$ nenê $)$ at $49.07 \%(\mathrm{SD} 4.94)[\mathrm{t}(244)=70.98 ; \mathrm{p}<0.001]$.

\section{Discussion}

The first goal of this study was to establish normative nasalance values for new speech stimuli, to be used with speakers of Brazilian Portuguese. Based on the main effect for stimulus and the post hoc Bonferroni comparisons, it was confirmed that the oral stimuli had the lowest scores, the oronasal stimuli had lower scores than the na- 
sal stimuli, and the nasal stimuli had the highest scores, as expected. Nasalance scores increase when the stimuli contain more nasal sounds, as has been demonstrated in different languages including Brazilian Portuguese [15], English [31], Spanish [36], Swedish [28] and Dutch [37].

It was not expected that age and gender would have significant effects on nasalance scores. This null hypothesis was rejected for gender and confirmed for age. Across all stimuli, the females' mean nasalance scores were 2 points higher than those for the males. Most of this difference could be attributed to the oldest age group where the females' mean nasalance score was 4 points higher than that of the males. While some previous studies have found no effect of gender [15, 24, 25, 28-30], others have found that women had higher scores than men on oral, mixed oronasal and nasal stimuli $[6,31-33]$. There was no main effect of age on nasalance scores, but there was an agestimuli interaction effect. Age differences were found for the traditional nasalance stimuli ZOO-BR and ZOO-BR2 [15], where the youngest group scored 2-4 points lower than the older groups. These findings were consistent with previous research in Brazilian Portuguese speakers [15]. Similar findings have been reported in other studies [2527], suggesting that growth may affect the oral-nasal balance. However, it should also be noted that such small differences may not be clinically relevant [6]. Normal dayto-day variation of nasalance scores may be in the range of $6-8 \%$ [38]. In further research, it would be interesting to investigate whether adults in middle age and older adults show further changes in oral-nasal balance.

Another goal of the study was to compare the new nasalance stimuli to the traditional stimuli [15]. It was expected that equivalent nasalance scores would be obtained for both sets of stimuli. This was important to ensure continuity with prior studies in Brazilian Portuguese. There were no significant differences between the pairs Dudu no zoo and ZOO-BR, Dudu no bosque and ZOO$\mathrm{BR} 2$, and $O$ nenê and NASAL-BR. While there were significant differences between the scores for Dudu no zoo and ZOO-BR2 as well as between Dudu no bosque and ZOO-BR, the magnitudes of the differences were $<3$ points. Therefore, it can be assumed that the newly developed materials are comparable to the existing materials used with Brazilian Portuguese speakers.

Two versions of the new oral nasalance stimuli were developed to give clinicians an option to match the stimulus to the language level of the speaker. It was expected that the oral nasalance stimulus Dudu no zoo and the shortened stimulus Dudu no bosque would have comparable mean nasalance scores. Although the statistical analysis found a significant difference, the magnitude of the differences was $<1$ point, meaning that the 2 stimuli may be considered sufficiently equivalent for clinical use.

The fourth goal was to characterize the articulation screening sentences in terms of their nasalance values, while the oral sentences with pressure consonants from the articulation screening had nasalance scores that were equivalent to Dudu no bosque. The low-pressure sentences differed significantly, albeit by a magnitude of $<1$ point, meaning that the 2 stimuli may be considered sufficiently equivalent for clinical use. The nasal sentences from the articulation screening had proportionally more nasal sounds than the nasal text passage $O$ nenê. Consequently, the nasal sentences from the articulation screening had significantly higher nasalance scores.

It can be speculated that a perceptual impression of hypernasality based on the articulation screening sentences should be equivalent to an assessment based on the nasalance stimuli. However, hyponasality may be more perceptually salient with the nasal articulation screening sentences than with the nasal passage $O$ nenê because of the higher content of nasal consonants. This should be taken into account whenever clinicians use the articulation screening sentences to make a perceptual assessment of oral-nasal balance.

The new nasalance stimuli should be particularly useful for younger patients or speakers with developmental or acquired cognitive or language disorders. The Brasilcleft articulation screening sentences expand the diagnostic tools for Brazilian Portuguese. Taken together, the new materials will allow a direct comparison of Brazilian patients with patients from international cleft centers who use assessments following the suggestions of the Beyond Eurocleft Group [39]. In future research, it will be important to analyze data from clinical subjects and assess whether the nasalance stimuli have equivalent diagnostic validity.

The current study was limited by the fact that none of the participants were either younger than 5 or older than 35 years. Previous research on nasalance across the life span has indicated that the nasalance scores for speakers under 5 years would probably not differ greatly from that for children in the 5- to 9-year age range [40]. Nevertheless, it will be important to establish norms for children younger than 5 years to document early speech outcomes after procedures such as primary palatoplasty.

While nasalance assessments are undertaken less frequently with older speakers, it would nevertheless be interesting to expand the study so that consistent data for different age brackets across the whole life span would be available. 


\section{Conclusion}

The nasalance scores for the new nasalance passages were equivalent to the preexisting materials. The new shortened and simplified nasalance passages will be useful for assessing young children. Normative scores for the Brasilcleft high-pressure sentences were equivalent to the new oral passage Dudu no bosque.

The study presents new nasalance stimuli and articulation screening sentences for Brazilian Portuguese. The new stimuli are overall equivalent to the traditional materials and may be useful for evaluating younger children and subjects with limited cognitive or attention skills. The averaged nasalance scores for the high-pressure sentences from the Brasilcleft articulation screening did not differ significantly from the oral new stimuli. However, the nasal sentences from the articulation screening have more nasal consonants than the nasalance stimuli, which needs to be taken into account in clinical assessments.

\section{Acknowledgments}

This study was supported by São Paulo Research Foundation FAPESP - grant No. 2012/23899-6. The authors thank the children, teenagers, parents and all adults who participated in this study.

\section{Disclosure Statement}

The authors declare no conflicts of interest.

\section{Appendix 1: Oral Passage (44 Syllables)}

Dudu no zoo (Dudu at the zoo)

Dudu visitou o zoológico

Lá viu o pulo do sapo

Gostou do lago cheio de peixes

Tirou foto dos bichos

Depois foi pra casa do vovô

\section{Appendix 2: Oral Shortened Passage}

Dudu no bosque (Dudu at the park)

Dudu visitou o bosque

Viu o pulo do sapo

Gostou do peixe

E tirou foto do sapo

\section{Appendix 3: Oronasal Passage}

O cãozinho Totó (Toto the puppy)

O cachorro do Nino

Se chama Totó

Ele come seu osso

E bebe água

Molha a bolinha

Corre o dia todo

E depois ele dorme

\section{Appendix 4: Nasal Passage}

O nenê (The baby)

Mônica mima o nenê

Veste seu pijaminha

Arruma seu bercinho

O nenê mama

Uma mamadeira toda

E depois nana

\section{Appendix 5: Articulation Screening Sentences (Brasilcleft Sentences Speech Stimuli)}

\begin{tabular}{lll}
$\begin{array}{l}\text { Target } \\
\text { consonant }\end{array}$ & Target sentence & English translation \\
\hline
\end{tabular}

High-pressure consonant sentence category

[p] Papai olha a pipa Dad sees the kite

[t] O tatu é teu The armadillo is yours

[k] O cuco caiu aqui The cuckoo clock fell here

[b] A Bibi babou Bibi drooled

[d] O dedo da Duda doeu Duda's finger hurt

[g] O Gugu é legal Gugu is cool

[f] A Fifi é fofa Fifi is cute

[s] O saci saiu Saci left

[S] Xuxa achou o chá Xuxa found the tea

[v] O vovô viu a vela Grandpa saw the candle

[z] A rosa é azul The rose is blue

[3] A Júlia é joia Julia is nice

Low-pressure consonant sentence category

$\begin{array}{lll}{[\mathrm{l}]} & \text { Lili olhou a lua } & \text { Lili looked at the moon } \\ {[\mathrm{x}]} & \text { Rui é o rei } & \text { Rui is the king } \\ {[\mathrm{l}, \mathrm{K}, \mathrm{r}]} & \text { Lulu olhou a arara } & \text { Lulu looked at the bird }\end{array}$

Nasal consonant sentence category

$[\mathrm{n}, \mathrm{m}] \quad$ O nenê mamou na mamãe

$[\mathrm{m}, \mathrm{n}] \quad$ A meia é minha

$[\mathrm{n}, \mathrm{m}, \mathrm{n}] \quad$ Aninha é minha mãe

The baby breastfed on his mother

The sock is mine

Aninha is my mom 


\section{References}

1 Kuehn DP, Moller KT: Speech and language issues in the cleft palate population: the state of the art. Cleft Palate Craniofac J 2000;7:348383.

2 Harding A, Grunwell P: Active versus passive cleft-type characteristics: implications for surgery and therapy. Int J Lang Commun Disord 1998;33:329-352.

3 Lohmander A, Olsson M: Perceptual assessment of speech in patients with cleft palate: a critical review. Cleft Palate Craniofac J 2004; 41:64-70.

4 Henningsson G, Kuehn DP, Sell D, Sweeney T, Trost-Cardamone JE, Whitehill TL; Speech Parameters Group: Universal parameters for reporting speech outcomes in individuals with cleft palate. Cleft Palate Craniofac J 2008; 45:2-17.

5 Howard SJ, Heselwood BC: Learning and teaching phonetic transcription for clinical purposes. Clin Linguist Phon 2002;16:371401.

6 Mayo CM, Mayo R: Normative nasalance values across languages. ECHO 2011;6:22-32.

7 Kim EY, Yoon MS, Kim HH, Nam CM, Park ES, Hong SH: Characteristics of nasal resonance and perceptual rating in prelingual hearing impaired adults. Clin Exp Otorhinolaryngol 2012;5:1-9.

8 Green JR, Yunusova Y, Kuruvilla MS, Wang J, Pattee GL, Synhorst L, Berry JD: Bulbar and speech motor assessment in ALS: challenges and future directions. Amyotroph Lateral Scler Frontotemporal Degener 2013;14:494500.

9 Hassan SM, Malki KH, Mesallam TA, Farahat M, Bukhari M, Murry T: The effect of cochlear implantation on nasalance of speech in postlingually hearing-impaired adults. J Voice 2012;26:669.e17-669.e22.

10 Kent RD, Vorperian HK: Speech impairment in Down syndrome: a review. J Speech Lang Hear Res 2013;56:178-210.

11 Keuning KHDM, Wieneke GH, Dejonckere $\mathrm{PH}$ : Correlation between the perceptual rating of speech in Dutch patients with velopharyngeal insufficiency and composite measures derived from mean nasalance scores. Folia Phoniatr Logop 2004;56:157-164.

12 Sweeney T, Sell D: Relationship between perceptual ratings of nasality and nasometry in children/adolescents with cleft palate and/or velopharyngeal dysfunction. Int J Lang Commun Disord 2008;43:265-282.

13 Tatchell JA, Stewart M, Lapine PR: Nasalance measurements in hearing-impaired children. J Commun Disord 1991;24:275-285.
14 Fairbanks G: Voice and Articulation Drillbook, ed 2. New York, Harper \& Row, 1960.

15 Trindade IEK, Genaro KF, Dalston RM: Nasalance scores of normal Brazilian Portuguese speakers. Braz J Dysmorphol Speech Hear Disord 1997;1:23- 34.

16 Fletcher SG: Contingencies for bioelectronic modification of nasality. J Speech Hear Disord 1972;37:329-346.

17 Mackay IR, Kummer AW: Simplified Nasometric Assessment Procedures. Lincoln Park, Kay Elemetrics, 1994.

18 Watterson T, Hinton J, McFarlane S: Novel stimuli for obtaining nasalance measures from young children. Cleft Palate Craniofac J 1996;33:67-73.

19 Watterson T, Lewis KE, Foley-Homan N: Effect of stimulus length on nasalance scores. Cleft Palate Craniofac J 1999;36:243-247.

20 Di Ninno CQMS, Vieira JM, Teles-Magalhães LC, Padovani CR, Pegoraro-Krook, MI: Determinação dos valores de nasalância para falantes normais do Portugues Brasileiro. ProFono 2001;13:71-77.

21 Sell DA, Harding A, Grunwell P: A screening assessment of cleft palate speech (Great Ormond Street Speech Assessment). Eur J Disord Commun 1994;29:1-15.

22 Sell D, Harding A, Grunwell P: GOS.SP ASS.'98: an assessment for speech disorders associated with cleft palate and/or velopharyngeal dysfunction (revised). Int J Lang Commun Disord 1999;34:17-33.

23 Dutka JCR: Brasilcleft: uma força-tarefa nacional para o gerenciamento dos resultados da correção da fissura labiopalatina. Revista Comunica, 2014, p 13. http://www.fonoaudiologia.org.br/cffa/wp-content/uploads/2013/07/revistacomunicar61.pdf.

24 Sweeney T, Sell D, O’Regan M: Nasalance scores for normal Irish-speaking children. Cleft Palate Craniofac J 2004;41:168-174.

25 Hirschberg J, et al: Adaptation of nasometry to Hungarian language and experiences with its clinical application. Int J Pediatr Otorhinolaryngol 2006;70:785-798.

26 Rochet AP, Rochet BL, Sovis EA, Mielke DL: Characteristics of nasalance in speakers of western Canadian English and French. J Speech Lang Pathol Audiol 1998;22:94-103.

27 Van Lierde KM, Wuyts FL, De Bodt M, Van Cauwenberge P: Age-related patterns of nasal resonance in normal Flemish children and young adults. Scand J Plast Reconstr Surg Hand Surg 2003;37:344-350.
28 Brunnegard K, Van Doorn J: Normative data on nasalance scores for Swedish as measured on the Nasometer: influence of dialect, gender, and age. Clin Linguist Phon 2009;23:5869.

29 Prathanee B, Thanaviratananich S, Pongjunyakul A, Rengpatanakij K: Nasalance scores for speech in normal Thai children. Scand J Plast Reconstr Surg Hand Surg 2003;37:351355

30 Lee A, Browne U: Nasalance scores for normal Irish-English speaking adults: a crossgender comparative study. Paper presented at the annual convention of the American Speech-Language-Hearing Association, Chicago, 2008.

31 Seaver EJ, Dalston RM, Leeper HA, Adams LE: A study of nasometric values for normal nasal resonance. J Speech Hear Res 1991;30: 522-529.

32 Van Lierde KM, Wuyts FL, De Bodt M, Van Cauwenberge P: Nasometric values for normal nasal resonance in the speech of Flemish adults. Cleft Palate Craniofac J 2001;38:112118

33 Mishima K, Sugii A, Yamada T, Imura $H$, Sugahara T: Dialectal and gender differences in nasalance scores in a Japanese population. J Craniomaxillofac Surg 2008;36:8-10.

34 World Health Organization: Young People's Health - a Challenge for Society. Report of a WHO Study Group on Young People and Health for All. Technical Report Series 731. Geneva, WHO, 1986.

35 Viaro ME, Guimarães Filho ZO: Análise quantitativa da freqüência dos fonemas e estruturas silábicas portuguesas. Estudos Linguist 2007;36:27-36.

36 Anderson RT: Nasometric values for normal Spanish-speaking females: a preliminary report. Cleft Palate Craniofac J 1996;33:333336.

37 Van der Heijden P, Hobbel HHF, Van der Laan BF, Korsten-Meijer AGW, GoorhuisBrouwer SM: Nasometry normative data for young Dutch children. Int J Pediatr Otorhinolaryngol 2011;75:420-424.

38 de Boer G, Bressmann T: Comparison of nasalance scores obtained with the nasometers 6200 and 6450. Cleft Palate Craniofac J 2014; 51:90-97.

39 Semb G: International confederation for cleft lip and palate and related craniofacial anomalies task force report: beyond Eurocleft. Cleft Palate Craniofac J 2014;51:146-155.

40 van Doorn J, Purcell A: Nasalance levels in the speech of normal Australian children. Cleft Palate Craniofac J 1998;35:287-292. 